\title{
Um Nietzsche diferente ${ }^{*}$
}

\author{
José Veríssimo**
}

Resumo: Artigo publicado em 1903, na primeira página do Correio da Manhã. Nele, o autor examina algumas das últimas publicações francesas das ideias de Nietzsche, bastantes conhecidas na época, inclusive no Brasil. Igualmente, procura avaliar a maneira como a filosofia nietzschiana começa a se tornar uma verdadeira moda na cena intelectual brasileira. E estabelece uma crítica que tende a ser negativa, tanto a respeito da recepção das ideias de Nietzsche na França quanto no Brasil, considerando o pensador ora como filósofo, ora como poeta.

Palavras-chave: Nietzsche - Sr. Roberty - pró-homem - Sr. Lichtenberger - Sr. Fouillée

Frédéric Nietzsche, par Eugène de Roberty, Paris. 1900. Cp. Les idées sociales de Nietzsche, par Alfred Fouillée. Revue des Deux Mondes de 15 de maio de 1902.

\section{Nietzsche está na moda, porque filosofias e filósofos também têm moda, como as casacas e os vestidos. Como filosofia de cada um, em regra geral, está, conforme diria um matemático, em função}

\footnotetext{
* Artigo publicado no Correio da Manhã. Rio de Janeiro, ano 03, N. 587, 19 de janeiro de 1903, p.1.

** José Veríssimo Dias de Matos (1857-1917). Crítico literário, membro fundador da Academia Brasileira de Letras. Em muitas passagens do texto aqui transcrito o autor apresenta uma linguagem - se comparada a outros críticos da época, como João Ribeiro, - um tanto conservadora e/ou arcaica, como é o caso do uso excessivo da pontuação de vírgula. Transcrevemos aqui a maneira como ele traduziu o vocábulo übermensch, oscilando entre "pró-homem" e "pró-homem".
} 
Veríssimo, J.

do seu temperamento, podemos crer que, quando uma filosofia ou um filósofo e suas doutrinas estão em moda, é que correspondem à índole do momento, ou, pelo menos, às aspirações e sentimentos, ao estado de alma de alma de grupos sociais, numerosos e consideráveis. E é, de fato, o que sucede a respeito de Nietzsche. No que se entrou a chamar modernamente os intelectuais, há uma porção importante, pela quantidade e pela qualidade, cuja filosofia pessoal é feita de individualismo, de pessimismo, quiçá de egotismo, de um anarquismo mental e sentimental, que tudo quisera destruir, para criar em lugar algo novo, onde a expansão do indivíduo encontrasse as máximas possibilidades, livre, enfim, de todos os "preconceitos" sociais, espirituais e morais, que a atrapalham e empecem. Essa porção caminhou resolutamente ao encontro do poeta filósofo de Assim Falou de Zaratustra, aclamou-o senhor e mestre, adaptou a sua doutrina contraditória e vaga, mas ensinada com insólita convicção e eloquência, nova e brilhante na formula, e que ao mérito intrínseco que acaso tinha juntava o de dizer com o temperamento e de corresponder aos sentimentos desses. Para muitos possuía ela ainda o encanto de lisonjear e satisfazer a sua vaidade de literatos, a sua fofice de estetas, que em antes mesmo de ter Nietzsche, nas pegadas de Emerson, de Carlyle, de Renan e de Taine, para não remontar mais alto, inventado o seu pró-homem (se esta palavra traduz bem o Übermensch de sua criação) se sentiam superiores a esta mofina e desprezível humanidade, e almejavam expandir a sua adorada pessoa consoante à desassombrada aspiração de sua vontade. Era uma filosofia para refinados, ou que se tem por tal, que, conforme o seu coração seco, a sua inteligência de egoístas e gozadores, dividia o mundo em senhores e escravos, em fortes e fracos, que fazia da produção dos grandes homens (quais são eles?) o fim único da existência do mundo, que condenava as nossas vulgares concepções de virtude, do bem, do amor, que endeusava, enfim, o egoísmo, a dureza, a crueldade, a violência, e mandava gozar a vida plenamente, sem atentar senão ao nosso próprio gosto, e sem respeitar nada do que à quase totalidade da gente parece respeitável e 
que outros filósofos, um Kant, um Comte, um Spencer, procuraram demostrar respeitável.

Foi assim, pelo menos, que o compreenderam não só os que se diziam seus discípulos, mas grande número dos que se lhe opuseram como adversários. Procurando no seu recente livro dar de Nietzsche uma ideia diversa desta, e interpretar a sua filosofia a uma luz diferente daquela em que tem sido vista por uns e por outros, escreve o sr. Roberty que o verdadeiro pensamento de Nietzsche "é a todo o momento traído, já por seus discípulos, já pelos seus adversários". E depois de convir que "o pensamento móbil" de Nietzsche explica tanto as inexatidões da interpretação comum como as da crítica esotérica, da sua obra, repara: "No seu livro sobre Wagner, nos descreve Nietzsche 'aquela pobre mocidade, petrificada numa postura de admiração, retendo o fôlego’ - São, diz ele, os Wagneristas; não compreendem palavra de música (que diria ele das nossas?), e todavia Wagner reina em nossas almas!. Esta piada poderia perfeitamente aplicar-se aos mais zelosos entre os modernos discípulos de Nietzsche: quantos deles nada entendem de filosofia, sobretudo da que ensinou o seu verdadeiro mestre!". Como isto é sobretudo verdade nestes Brasis!.

Eu não poderia dizer até que ponto é exata a interpretação nova que de Nietzsche nos dá o sr. Roberty, um dos estudiosos e escritores de filosofia mais copiosos e bem reputados do atual movimento filosófico europeu. Mas ele mesmo não parece ter - e o confessa - uma grande confiança no seu novo Nietzsche. Ora quando tantos sabedores eminentes de filosofia, críticos argutos, exercem a sua ciência, a sua crítica, os métodos lógicos melhormente provados na indagação de uma obra filosófica, e não chegam senão a divergências essenciais; quando discípulos e adversários dessa obra não logram compreende-la, segundo o parecer de outros críticos, e os mais simpáticos, como o sr. Roberty; quanto, enfim, entre os seus interpretes, admiradores ou contrários, reine a mais radical contradição na maneira de entendê-la e explicá-la, não temos nós, vulgo ignaro, o direito de logicamente concluir que ela é de si mesma 
Veríssimo, J.

vaga, imprecisa, incoerente, contraditória, vária, inconsequente, e que, portanto, é justamente o oposto de toda a concepção de mundo e da vida, que mereça o nome de uma filosofia? Parece-me que sim, e o livro do sr. Roberty não logrou desconvencer-me de que Nietzsche não pertence à linhagem, para não sair dos tempos mais próximos, dos Hegels (apesar do que ainda de vago e impreciso se possa achar na filosofia hegeliana), dos Kants, dos Comtes, e dos Spencers, nem mesmo Schopenhauer, seu mestre imediato. Não direi como Tolstoi - que não é um leigo em filosofia - que a de Nietzsche "apenas é um palavreado imoral, grosseiro, empático e incoerente", mas como disse da primeira vez que tive ocasião de estudar Nietzsche, através do mais considerado dos seus expositores franceses, o sr. Lichtenberger, a sua filosofia é puramente a filosofia de poeta genial, como é a de Ruskin, por exemplo. Bem razão teve o sr. Renouvier quando, ao mostrar, com a sua alta autoridade filosófica, o filósofo que havia em Vitor Hugo, afirmou que na filosofia do poeta não havia talvez mais incoerência que na de filósofos dados por tal. Pensaria o eminente neokantista francês em Nietzsche? É bem possível. Em um curto mas incisivo artigo da Revue des Deux Mondes, pôs o sr. Fouillée em evidência aquilo que a qualquer leitor de Nietzsche salta aos olhos: o vago, o incoerente, o versátil das suas lucubrações, e a impossibilidade de fazer delas uma filosofia, senão no mesmo sentido em que falaríamos numa filosofia de Shakespeare, de Goethe, ou de Hugo.

Embora considerando o nietzscheanismo como um "movimento intelectual que desperta a mais preguiçosa atenção, um fato metal que impressiona e surpreende por seu inegável valor sintomático, uma atitude, nada comum de pensamento em face do mundo", o sr. Roberty acha-o "antes magra ontologia e suntuosa filosofia social" que "uma nova doutrina, poderosa, rica de seiva que ascendesse ao trono vago da filosofia". Conquanto "espíritos prontos ao entusiasmo fácil" se comprazam em esperá-lo, ele, compreendendo "a sua ilusão", não a compartilha. 
Não é, pois, como um filósofo sistemático, nem como uma filosofia que ele estuda Nietzsche e as suas versáteis doutrinas, mas nestas, e é estas que principalmente estuda, enxerga o sr. Roberty uma adição considerável às ideias filosóficas e sociais do século XIX.

Não é minha intenção, e seria impertinente num artigo de jornal, trazer para aqui a argumentação, talvez demasiado técnica, do novo critico de Nietzsche. Pareceu-me, entretanto, - ousarei dizê-lo - que, pretendendo manter uma posição média e imparcial entre os idólatras e os detratores do autor de Zaratustra, o sr. Roberty cedeu mais do que era lícito ao encanto do alto e original poeta, e tomou demasiado a serio as suas às vezes sublimes, mas também às vezes deprimente divagações e imaginações. Sobretudo se lhe poderia notar como, à força de querer ver em Nietzsche não o individualista decidido, o egoísta seco, o imoralista cínico, que aliás o tornaram querido dos estetas que ridicularmente já se supunham uns "pró-homens", mas um pensador generosamente otimista e humano, um sociólogo de vistas claras e bem facejas, que apenas vale o seu real amor humano, o seu senso de progresso, a sua aspiração por um mundo e uma humanidade melhores sob o véu esfumaçado do simbolismo, ou sob a nebulosidade ofuscante de seu verbo de poeta, a análise do sr. Roberty se faz demasiado sutil, quiçá especiosa, mais arguciosa e casuística, que honestamente lógica, ou simplesmente penetrante. É o defeito e perigo das nossas interpretações a todo o transe de pensadores e poetas, nos quais descobrimos as obscuridades e dificuldades, e ocultos sentimentos e intenções que, na maioria dos casos, não estariam na sua mente, mas que condizem com nosso próprio pensar e sentir. Depois de haver sido um positivista-litreísta, o sr. Roberty, passando talvez pelo evolucionismo spenceriano, com o seu agnosticismo, estanceou numa espécie de monismo, em que se pretende original, e que expôs com talento, mas certa obscuridade e peso de expressão, em variadas obras de crítica e doutrina filosófica. Não é de modo algum um positivista, como já o declarou num opúsculo em que dizia por que o não era; mas a impressão da unha poderosa de Comte ficou-lhe marcada no cérebro. 
Assim, a cada passo do seu exame de Nietzsche, procura ele reduzir as difíceis e vagas fórmulas nietzschianas aos princípios das suas próprias, ou de outras, contadas como sistemas filosóficos e particularmente as do positivismo.

O seu processo geral da exposição e crítica da filosofia de Nietzsche é expor em síntese a opinião mais geral sobre algum aspecto dessa filosofia, examiná-la e concentrá-la, dizendo-a sua. Assim ao conceito de que "a filosofia de Nietzsche, sobretudo a sua filosofia moral, era um protesto do Instinto - e mais particularmente o instinto de potência ou de grandeza - contra a lógica e sua velha prepotência nas coisas humanas", - "uma revolta da vida, do mundo orgânico, contra a sociedade, o mundo sobre-orgânico", responde o sr. Roberty que, "se tal fosse o caso, devia-se condenar o pensamento de Nietzsche como infinitamente pobre e medíocre". E procura convencer-nos que, ao contrário, Nietzsche "é um lógico", e que apesar de ter num dos seus livros gritado raivoso que nada tinha com as refutações, os seus livros são, em vez de "uma pura interjeição, um longo brado de dor e de revolta, da lástima de um nobre espírito pelas duras realidades da vida, uma refutação incessante". Assim por diante.

Nietzsche despreza ou odeia a multidão, como afirmam alguns dos seus críticos, uns para reprová-lo, outros aplaudi-lo? Não, diz o sr. Roberty, e dá as suas razões: "o que ele quer é a elevação de cada um e de todos, é a aristocratização da multidão"; somente "ele não se impressiona com a contradição aparente que parece existir entre estes dois termos". Também Nietzsche, segundo o nosso autor, "não foi o antidemocrata e o anti-socialista que habitualmente nos pintam. Seu socialismo, porém, como seu altruísmo, excede o nível estabelecido pela história" - quer dizer sobrelevam as nossas condições e concepções presentes, apontam a um futuro remotíssimo, a cuja realização este singular altruísta manda de boa mente e cara alegre sacrificar tudo o que nos parece digno de compaixão - uma compaixão que ele maltrata em violentas diatribes - o miserável, o fraco, o pobre, e com eles o nosso senso de justiça, a nossa ideia de 
liberdade, o nosso sentimento de amor e de solidariedade humana. Mas não, nós nos enganamos, e conosco enganam-se os que se dizem discípulos de Nietzsche. O niilismo moral de Nietzsche, como às suas doutrinas morais chamaram, "prova um ardente desejo de moral superior. Salvo talvez Spinoza - que exteriormente se conservava calmo e objetivo - ninguém amou o Bem com tal veemência e detestou o mal tão fogosamente. Acontece-lhe, em verdade, glorificar em termos magníficos os vaidosos e os mal; longe, porém, de ser arrastado a isso pela fria consideração do interesse do espectador curioso, do amador dos grossos dramas da vida, como acreditaram e disseram os seus discípulos iludidos por sua ironia transcendente , o faz porque do mal imediato que produzirá entre os homens a ação vaidosa e má, espera (e com tanta razão!) a germinação de um Bem novo, desconhecido, muitíssimo superior ao Bem atual". Mal comparado, é um pouco como Nero incendiando Roma (se foi ele quem a incendiou) para levantar sobre os seus escombros uma nova e muito mais bela cidade.

E o famoso Próhomem, "cujo conceito é um ponto culminante do evangelho moral promulgado por Nietzsche"? Esta teoria "é a tempo hipótese e símbolo". Como hipótese, acha o sr. Roberty que ela "data de longo" e assemelha-a "a conjectura que excitou o zelo de Condorcet e contribuiu a fundar o socialismo, de um progresso indefinido do gênero humano. E em nota ainda o traz de mais longe, "do homem que vive segundo a razão", de Spinoza. É quase certo que se lhe podia encontrar a genealogia ainda mais remotamente. Modernamente Emerson (de quem não fala o sr. Roberty) e Carlyle são seus progenitores mais imediatos. Decididamente nada há novo debaixo do sol; já o velho Horácio (Odi profanum vulgus...) e o nosso Camões ( $O$ vulgo vil sem nome), pro-homens segundo a concepção nietzschiana, tinham pouco estima pelo rebanho humano. Ao símbolo do dito pró-homem acha o sr. Roberty "uma origem mais recente. $\mathrm{O}$ advento do pro-homem designa a queda irremediável das ideias morais de que se glorifica o homem contemporâneo... 
Nascido da ideia de iluminada perfectibilidade da natureza humana, assinala o pro-homem a modificação mais urgente que, custe o que custar, se deverá realizar nessa natureza".

Nietzsche é, como filósofo, sobretudo um anarquista, que sonha uma sociedade futura e melhor, e cujo advento, segundo a sua linguagem, depende de uma "transmutação de valores" - isto é, dos fatos morais em que se baseia a sociedade atual por outros fatos. Daí o aspecto cruel, egoísta, cínico por vezes da sua doutrina, ou melhor, das suas colossais imaginações filosófico-sociais. Já vimos que seu amor ao Bem é tal, que ele aplaude o Mal que apressasse a realização do Bem. No fundo um otimista, mas um otimista que odeia profundamente o presente, e que por amor do futuro, como o imagina, condenaria a piedade e o amor, e todas as instituições sociais e concepções morais que o fazem viver. "Pedir à vida que seja bela", escreve o sr. Roberty, acreditando que é o que faz Nietzsche, "é sobretudo pedir-lhe que seja verdadeira e sincera. E tratando-se dessa fração da vida chamada conduta humana, é pedir-lhe ainda que seja justa, porque a justiça é o nome da verdade no domínio social, na esfera estrita das relações que unem os homens entre si”.

Não me sinto competência (ou atrevimento, que aqui tão comumente a supre) para dizer se a nova interpretação de Nietzsche do sr. Roberty é verdadeira ou a verdadeira. Mas, sobre cheia de talento e poder filosófico, é que faz menos antipático, que faz mesmo sintático, o poeta de Zaratustra.

\begin{abstract}
Article published in 1903, on the first page of the Correio da Manhã. In this article, the author examines some of the last French publications of Nietzsche's ideas, largely known at the time, also in Brazil. It also seeks to assess the way how Nietzschean philosophy starts to become a real trend on the Brazilian intellectual stage. And it establishes a criticism that tends to be negative, concerning both the reception of Nietzsche's ideas either in France or in Brazil, considering the thinker times as a philosopher, at other times as a poet.
\end{abstract}

Keywords: Nietzsche - Sr. Roberty - pro-man - Mr. Lichtenberger - Mr. Fouillée 